\title{
EL GUERNICA EN LA CALLE DURANTE LA TRANSICIÓN Y LOS PRIMEROS AÑOS DE LA DEMOCRACIA
}

\author{
ISABEL GARCÍA GARCÍA \\ Universidad Complutense de Madrid
}

\begin{abstract}
Durante la dictadura y después de ésta, el Guernica devino símbolo no sólo de una búsqueda desesperada por la libertad perdida sino también de una búsqueda de identidad por parte del pueblo vasco. La Asociación de Artistas Plásticos de Madrid y el artista vasco Agustín Ibarrola desempeñaron un importante papel en este sentido. Este artículo reúne documentación inédita acerca de los artistas y sus murales, y contribuirá a añadir un nuevo significado sociopolítico del Guernica en los últimos años de la década de los setenta.

Palabras clave: Picasso; Guernica; Arte y política; Asociación de Artistas Plásticos; Agustín Ibarrola.
\end{abstract}

\section{GUERNICA ON THE STREET DURING THE TRANSITION AND FIRST YEARS OF DEMOCRACY}

During the Spanish dictatorship and afterwards, Picasso's Guernica became a symbol not only of a desperate search for lost freedom, but also of a quest for identity of the Basque people. In Madrid, the Asociación de Artistas Plásticos (Visual Artists' Association) and the Basque artist Agustín Ibarrola played leading roles in this quest. This essay unites unpublished documentation concerning these artists and their street murals, and adds new socio-political meaning to Guernica during the late seventies.

Key words: Picasso; Guernica; Art and politics; Asociación de Artistas Plásticos; Agustín Ibarrola

La muerte de Picasso el 8 de abril de 1973 reabrió el eterno debate sobre la situación legal y (cuál sería) el lugar idóneo para albergar el enorme lienzo de 349,3 × 776,6 cm, custodiado desde la década de los cuarenta por el Museo de Arte Moderno de Nueva York.

Sin embargo, mucho antes, incluso durante los meses de mayo y junio de 1937, en los que Picasso estaba realizando el Guernica, la obra estaba construyendo su propia leyenda. Una parte importante de ello se debió al proceso fotográfico que Dora Maar realizó al cuadro y a que, poco después, algunas de aquellas imágenes serían publicadas en la prestigiosa revista francesa $\mathrm{Ca}$ hiers d'Art y en la revista valenciana Nueva Cultura. Esa repercusión mediática no sería más que el comienzo de todo un proceso que en nuestros días continúa su recorrido.

Convertido en uno de los símbolos más conocidos de los siglos XX y XXI, no ha dejado de generar nuevos significados pero, sin duda, los de libertad y sufrimiento han sido los más acla- 
mados por todos. Y no es para menos: las terribles circunstancias que rodearon este episodio de la historia son bien conocidas. Como lo fueron también los numerosos bombardeos que se llevaron a cabo durante todo el siglo XX. En este sentido, no es fácil olvidar algunas propuestas de muchos artistas posteriores en las que está presente el Guernica como símbolo pacifista; por ejemplo la de Rudolf Baranik, quien diseñó el cartel Stop the War in Vietnam Now! (1967) o la protesta en el MOMA del Grupo AWC (1970) para defender los derechos de igualdad durante la guerra de Irak. Hace unos meses, incluso, se acaba de exponer en la feria de Dubái otra versión del mural de Picasso, The new Guernica (2013). Realizado por el artista exiliado Oussama Diab estamos, una vez más, ante un símbolo de condena y repulsa sobre un conflicto, en esta ocasión la actual guerra siria.

En la historia reciente de España ${ }^{1}$, concretamente durante la dictadura y después de ésta, el Guernica fue símbolo no sólo de una búsqueda desesperada por la libertad perdida sino también de una búsqueda de identidad por parte del pueblo vasco. Estas dos premisas, libertad e identidad, centrarán gran parte de esta investigación ${ }^{2}$.

Empecemos por la primera. De todos es sabido que, durante la dictadura, Picasso -sobre todo cuando se afilió al Partido Comunista francés en los años cuarenta- se convirtió en uno de los enemigos del régimen aunque su aura internacional fue tan decisivo - tanto artística como sociopolíticamente hablando para una gran mayoría de exiliados españoles- que terminó por convencer al Caudillo e iniciar una serie de conversaciones para determinar posibles donaciones al Estado español. Franco había puesto en marcha a finales de 1968 la llamada "Operación regreso" del Guernica a España. Y eso a pesar de haber sido encargada y exhibida en el pabellón del gobierno republicano para la Exposición Internacional de París (1937) y de dar a conocer allí la peculiar visión de Picasso sobre las andanzas de un caballero ridículo en Sueño y mentira de Franco, realizado en las mismas fechas que el Guernica ${ }^{3}$.

Durante los últimos años de la década de los sesenta, puesta en marcha esa llamada etapa de apertura de España al extranjero, con la estabilización y el desarrollo se hace más patente una creciente oposición al Régimen. Una gran mayoría de los artistas españoles había comenzado a luchar por la amnistía, la libertad de expresión, de reunión y de asociación perdidas durante el franquismo. En estos momentos comienza a configurarse la Asociación de Artistas Plásticos. Una asociación ilegal que nacía de los esfuerzos de muchos y que había sido constituida tras varias asambleas en la Escuela de Bellas Artes de Madrid, en donde quedaron establecidas varias comisiones de trabajo, centradas en las funciones del arte en la sociedad, en los canales de difusión, en la elaboración de unos estatutos para el artista o en la problemática de la enseñanza de las bellas artes.

Sin embargo, y ante la prohibición de fundar una asociación de artistas plásticos, se pensó ingresar en la Organización Sindical Española, conocida como el Sindicato Vertical (1940-1976) y que estaba dividida a su vez en varias ramas de producción. En el caso de las artes, bajo la acogida de ANSIBA (Asociación Nacional Sindical de Bellas Artes), pero finalmente ese intento fue rechazado por la incompetencia de la entidad. En 1972 se pergeñó un nuevo modelo de agrupación llamada APSA, Promotora de Actividades Plásticas (Sociedad Anónima), y próxima al Partido Comunista de España, como se pudo comprobar el 25 de abril de 1975, cuando se orga-

\footnotetext{
${ }^{1}$ La reconstrucción de este episodio ha sido posible gracias a la generosa ayuda del fotógrafo Heinz Hebeisen y del artista Ángel Aragonés.

2 Este texto se enmarca dentro de los proyectos de investigación Tras la República: redes y caminos de ida y vuelta en el arte español desde 1931. P.N. de I+D+i, Ref: HAR2011-25864 y Arquitectura, urbanismo y representación en la construcción de la imagen de los barrios: I+ D Ref: HAR 2012-38899-C02-02.

${ }^{3}$ Haro González y Soto Calzado, 2011: 15-28.
} 
nizó la primera junta democrática de los artistas plásticos de Madrid, en busca de mayores libertades y autonomías ${ }^{4}$.

Ante el enorme vacío cultural creado desde 1939, agravado con la prohibición de cualquier manifestación cultural no afín al régimen y el desamparo total del artista ante la sociedad, se redactó una petición de siete derechos básicos para la futura Asociación de Artistas Plásticos: libertad de reunión, asociación y expresión; amnistía para los artistas represaliados por razones culturales o ciudadanas; democratización del acceso y difusión de la cultura por medio del establecimiento de cauces no comerciales y de la autogestión; abolición de la censura; participación en la política cultural a todos los niveles; reforma de la enseñanza de las artes plásticas y control del patrimonio artístico nacional ${ }^{5}$.

Estas demandas de los artistas plásticos están relacionadas con los "doce puntos" exigidos por el PC como una de las posibles vías para la evolución democrática del Estado franquista. Fueron redactados en 1974, un año antes de la aparición del Comunicado de Constitución de la Junta Democrática de Artistas Plásticos de Madrid, por Antonio García-Trevijano:

"1. La formación de un gobierno provisional que sustituya al actual, para devolver al hombre y a la mujer españoles, mayores de dieciocho años, su plena ciudadanía mediante el reconocimiento legal de todas las libertades, derechos y deberes democráticos.

2. La amnistía absoluta de todas las responsabilidades por hechos de naturaleza política y la liberación inmediata de todos los detenidos por razones políticas o sindicales.

3. La legalización de los partidos politicos, sin exclusiones.

4. La libertad sindical y la restitución al movimiento obrero del patrimonio del Sindicato Vertical.

5. Los derechos de huelga, de reunión y de manifestación pacifica.

6. La libertad de prensa, de radio, de opinión y de información objetiva de los medios estatales de comunicación social, especialmente en la televisión.

7. La independencia y la unidad jurisdiccional de la función judicial.

8. La neutralidad politica y la profesionalidad, exclusivamente militar para la defensa exterior, de las Fuerzas Armadas.

9. El reconocimiento, bajo la unidad del Estado español, de la personalidad política de los pueblos catalán, vasco, gallego y de las comunidades regionales que lo decidan democráticamente.

10. La separación de la Iglesia y del Estado.

11. La celebración de una consulta popular, entre los doce y los dieciocho meses-contados desde el día de la restauración de las libertades democráticas-, con todas las garantías de libertad, igualdad de oportunidades e imparcialidad, para elegir la forma definitiva del Estado.

12. La integración de España en las Comunidades europeas, el respeto a los acuerdos internacionales y el reconocimiento del principio de la coexistencia pacífica internacional".

El apoyo de los artistas plásticos a este guión político del PC, junto al suyo, creó un caldo de cultivo idóneo entre los sectores culturales y ciudadanos más desprotegidos que facilitó el desarrollo de grandes movilizaciones democráticas. En este sentido, la imagen del Guernica se convertirá en un símbolo de libertad en todos sus aspectos. Así, en 1975 y bajo las siglas de APSA

\footnotetext{
${ }^{4}$ Un año antes, en julio de 1974, se había constituido en París, la primera Junta Democrática de España del Partido Comunista de España (PCE), como oposición al franquismo y como intento de articular una gran masa social mediante Juntas democráticas locales y sectoriales.

5 Comunicado de Constitución de la Junta Democrática de Artistas Plásticos de Madrid, 25 de abril de 1975, Centro de Documentación y Biblioteca MNCARS, Madrid, SIG. 875/7.

${ }^{6}$ Estos puntos también aparecen redactados en el Comunicado de Constitución de la Junta Democrática de Artistas Plásticos de Madrid, 25 de abril de 1975, Centro de Documentación y Biblioteca MNCARS, Madrid (en adelante CDB/MNCARS), SIG. 875/7.
} 
(Promotora de Actividades Plásticas. Sociedad Anónima), comenzaron a realizarse algunas actividades donde la reproducción del Guernica estuvo presente.

Una de las primeras, y desde luego desconocida para muchos, fue la realización por el artista valenciano Josep María Gorris de un juguete alusivo al Guernica ${ }^{7}$. APSA, siguiendo los pasos de otros grupos anteriores como Equipo 75 o Estampa Popular ${ }^{8}$, centró su producción en mensajes artísticos antifranquistas, un arte con función social y en la creación de obra múltiple (grabados) de comprensión sencilla; de hecho, algunos de sus miembros como Agustín Ibarrola, José Duarte o Juan Serrano formaban parte de esta nueva asociación. Dentro de estos parámetros, también la artesanía y las artes populares habían sufrido un gran deterioro y, en ocasiones, el abandono o la desaparición ${ }^{9}$. Un ejemplo de ello era la lamentable situación del Museo del Pueblo Español, creado en 1934, frente a la producción masiva de la "Fundación Generalísimo Franco. Industrias Artísticas Agrupadas" (1941) que obstaculizaba la aparición de un nuevo proceso artesanal. Por ello, en la colección del año 1976-1977 se decidió que junto a las ediciones de grabado de APSA $^{10}$ se vendería un juguete múltiple "de gran originalidad e ingeniosa concepción"ll que representaba al Guernica.

\section{El Guernica de Picasso, a Guernica}

Otros hechos, mucho más visibles, fueron las acciones murales en forma de protesta para insistir en los problemas de los barrios más degradados de Madrid, como los de Portugalete o Del Pilar. En ambas estuvo presente la imagen del Guernica.

Aquel verano de 1975, que significó el prefacio del derrumbamiento del régimen, comenzó con las graves noticias a las que la dictadura de Franco tenía acostumbrado al país: detenciones masivas, aumento de la represión, consejos de guerra o condenas a muerte. En ese ambiente de crispación tuvo lugar una protesta de carácter artístico en el barrio de Portugalete.

Considerada como una toma de conciencia ciudadana, un modelo de arte comunitario, de arte popular y de tantos otros adjetivos ${ }^{12}$, lo cierto es que fue una maniobra político-intelectual llevada a cabo por un grupo mayoritario de artistas comprometidos con organizaciones sindicales y bajo el nombre, aún ilegal, de la ya mencionada Asociación de Artistas Plásticos. Aquellas pintadas ocuparon más de $500 \mathrm{~m}^{2}$ de muro, junto a un fragmento de la imagen del Guernica firmado por el equipo del barrio de Portugalete (fig. 1) y otras tantas obras de todos los tamaños, temáticas y estilos ${ }^{13}$.

\footnotetext{
7 Vid. GORris, 1981.

8 Vid. De Haro García, 2010.

${ }_{9}$ Nos encontramos en un momento donde las artes populares son requeridas de nuevo por muchos artistas. De hecho ese regreso a la cerámica popular puede verse en el número extraordinario de la revista Batik. "Extraordinario Cerámica. Una panorámica de la cerámica contemporánea española”, núm. 44, VI año, Madrid, octubre de 1978.

${ }^{10}$ En la colección de grabados de aquel año se presentaban los siguientes artistas: Clara Gangutia, Natividad Gutiérrez, Paco Álvarez, José Duarte, Pepe Pla, Salvador Soria e Isabel Vázquez.

11 Documento de APSA fechado el 16 de marzo de 1976 y carta de la Promotora de Actividades Plásticas (APSA) a los artistas, 16 marzo de 1976. Archivo personal del artista Ángel Aragonés.

12 "En el barrio de Portugalete, artistas y vecinos llevan el arte a las tapias y paredes medianeras", Informaciones, Madrid, 23-VI-1975; "Los artistas del barrio", Triunfo, Madrid, 12-VII-1975; BALLESTER, José MARÍA, “Arquitectura y urbanismo", Blanco y negro, Madrid, 5-VII-1975; CABEZAS, "Mentidero de la villa. Fiestas y cultura popular en Portugalete", $A B C$, Madrid, 30-VI-1976; DE Prado, "Quieren formar sus juntas de compensación”, Arriba, Madrid, 10-VII1975; GiL MintXa, "Arte en la calle para la calle”, Gaceta Ilustrada, Madrid, 1-VII-1975; MuÑoz García, "Los murales y la estética urbana", Gazeta del arte, Madrid, 30-IX-1975; Prieto Barral, María Fortunata, "L'art dans la rue á Madrid”, Galerie jardins des arts, Paris, XII-1975 y Pyresa, "Una manifestación artística inédita”, Sur, 15-VII-1975.

13 Vid. García García, 2013: 477-490.
} 


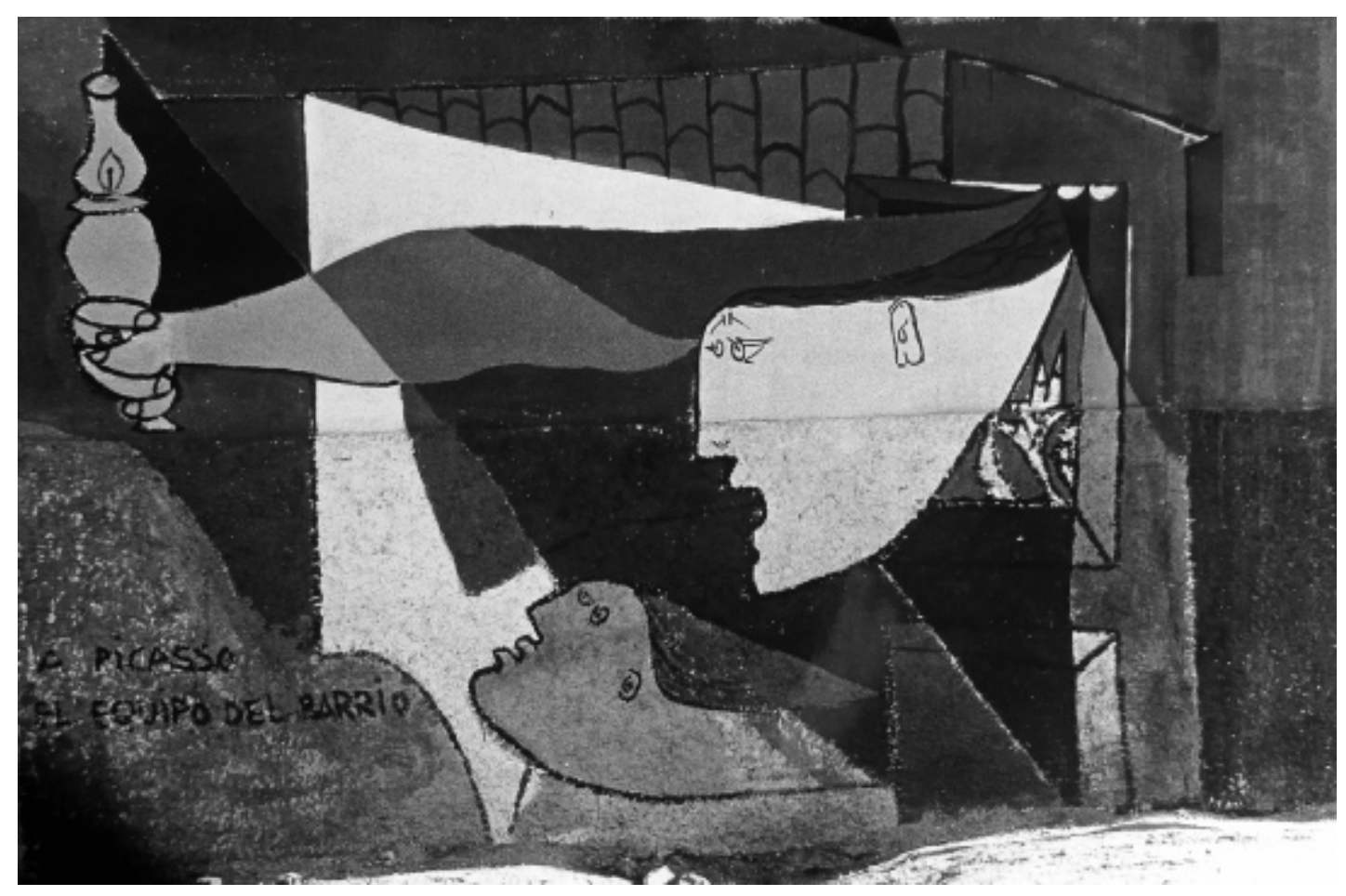

Fig. 1. Mural del barrio de Portugalete, Madrid, 1975. Foto: Heinz Hebeisen.

Frente al emblema de libertad que se forjó alrededor del Guernica se contrapusieron en el barrio otras imágenes que aludían directamente al dictador. Muchas de ellas, sin duda, conocidas por los que allí estuvieron. Sin embargo, me gustaría destacar el mural de la descomposición de Franco realizado por Zamorano como indicativo de una agónica época que parecía terminar.

Al año siguiente, y después de la muerte de Franco, la celebración de las siguientes fiestas del Barrio de Portugalete tuvo como protagonista, de nuevo, la recreación del gran mural del Guernica, incluso con las mismas dimensiones que el original. Nos encontramos en un momento especialmente delicado, ya que se reaviva el debate sobre la vuelta del Guernica a España y es entonces cuando Agustín Ibarrola y el equipo de plásticos de Euskadi pintan para Portugalete Guernica obra de Picasso exiliada en USA propiedad de los pueblos de España (fig.2).

La relación de Ibarrola con los Plásticos se pone de manifiesto a finales de los años sesenta cuando algunas Escuelas de Bellas Artes como la de Madrid, Euskadi o Sevilla inician una serie de asambleas para ofrecer alternativas democráticas a la enseñanza de las Bellas Artes y coordinar a todos los artistas de España. Los manifiestos se centran, sobre todo, en la reforma de la enseñanza de las artes plásticas ${ }^{14}$. En líneas generales, se trataba de crear una universidad libre, democrática y popular. Fruto de estas reuniones nacen en Euskadi cuatro grupos que conforman el Movimiento de la Escuela Vasca: Grupo Gaur (Guipúzcoa), Emen (Vizcaya), Orain (Vitoria)

${ }^{14}$ Entre aquellas propuestas destacan la creación de un "Plan de estudios racional, de acuerdo con nuestras necesidades y exigencias, en el cual, a través de una formación humanística y de teoría y práctica de la plástica, con los métodos y técnicas más avanzados y adecuados, traiga como consecuencia la capacitación y el ejercicio de la actividad creadora y pedagógica”. Documento del archivo personal del artista Ángel Aragonés. 


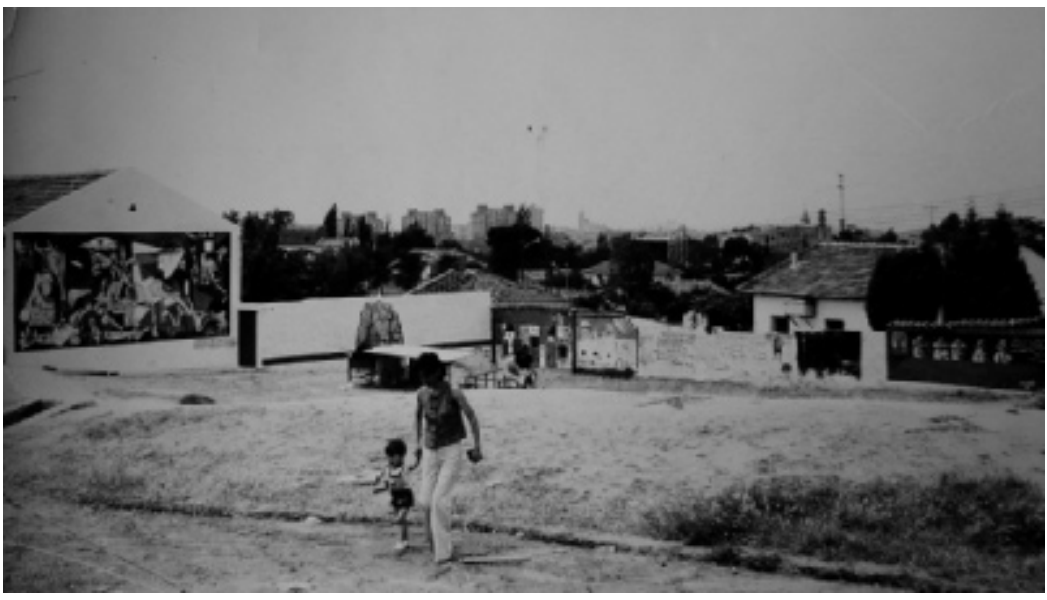

Fig. 2. Mural del barrio de Portugalete, Madrid, 1976.

y Danok (Navarra) que se asientan en expresiones reivindicativas del carácter nacional de la cultura de pueblo vasco. Sin embargo, las desavenencias entre ellos impiden la toma de decisiones de forma colectiva.

El grupo de Vizcaya se mostrará más cercano a las decisiones de la Asociación de Artistas Plásticos de Madrid. En junio de $1976^{15}$ se celebra una asamblea en la Escuela de Bellas Artes formada por más de ciento veinticinco artistas y en la que se debatían los estatutos elaborados con un ente jurídico para constituir una formación legal para la futura Asociación de Artistas Plásticos. Allí quedaban explícitas las diversas formas asociativas y la manera de acceder a ellas. Entre éstas se debatieron tres posibilidades: una, constituir un Colegio Profesional; otra, configurar un Colegio Sindical y la última, formar una Asociación siguiendo la Ley de año $1964{ }^{16}$ que fue la que, finalmente, se eligió ${ }^{17}$. Los artistas plásticos de Vizcaya -Sol Panera, José Ibarrola, Agustín Ibarrola, Patxi Cobo, Dionisio Blanco, Miguel Ángel Hermosilla, Iñaki de la Fuente, Adolfo Martin “Arri” y Javier Urquijo- dieron su apoyo por escrito a la aprobación del Anteproyecto de los Estatutos para crear un Colegio Nacional de Artistas Plásticos:

"consideramos de enorme interés para el desarrollo de nuestra profesión, y teniendo en cuenta la imposibilidad momentánea de la creación del colegio autónomo por el que abogamos, nos sumamos plenamente al texto del anteproyecto, optando por una solución en forma de delegación del colegio central en Euskadi"18.

15 El Orden del día fue el siguiente: 1. Presentación y resumen de la asamblea anterior, 2. La comisión de estudios de Estatutos dará lectura a su trabajo de base "Hacia unos estatutos definitivos para los Artistas Plásticos", 3. Esta misma comisión dará lectura a trabajos realizados por diversos juristas, sobre los diversos aspectos asociativos en el sector, 4. Ruegos y preguntas y por último, conclusiones. Documento del archivo personal del artista Ángel Aragonés.

16 Documento Acta de la Asamblea realizada el 30 de junio de 1976 en la Escuela Superior de Bellas Artes, CDB/ MNCARS, SIG. 875/1.

17 Sin embargo y ante los continuos rechazos por parte de la administración, no sería hasta la aparición de la Ley 19/77 reguladora del Derecho Sindical cuando, por fin, conseguirían su completa legalización.

18 Documento Declaración de los plásticos de Vizcaya en la Asamblea de Madrid para aprobar el anteproyecto de Estatutos del Colegio Nacional de Artistas Plásticos, junio de 1976, CDB/MNCARS, SIG. 896/1. 
Volvamos al asunto del Guernica. No era la primera vez que Ibarrola introducía este argumento en sus obras. A mediados de los 60 y tras su paso por la cárcel realizó varios trabajos donde aparecen fragmentos del Guernica para expresar, según el artista, los "nuevos guernicas" de Euskadi ${ }^{19}$. El mensaje ideológico se vio justificado con un clima de nuevas manifestaciones, estados de excepción, falta de control, etc.; pero más interesante aún fue la representación en los muros vascos de estos modelos contrapuestos. Al lado de la imagen del Guernica de Picasso las semejantes figuraciones geométricas de Ibarrola, con el lema "Gernika... Mañana todo Euskadi" (fig. 3). La alusión al problema vasco era más que directa, desde luego si se recuerda que no fue el único caso aislado. Por ejemplo, destaco el Homenaje a Guernika de Picasso de José Luis Zumeta, miembro del grupo vasco Gaur, y ganador con esta obra en el año 1967 del Primer Premio del III Gran Premio de Pintura Vasca. Diálogo entre el antibelicismo y la visión identitaria del bombardeo. O, también, los murales del movimiento comunista de Euskadi reproduciendo el Guernica. Un período en donde el lema "Guernica Gernikara" (El Guernica a Gernika) fue difundido por todo el País Vasco.

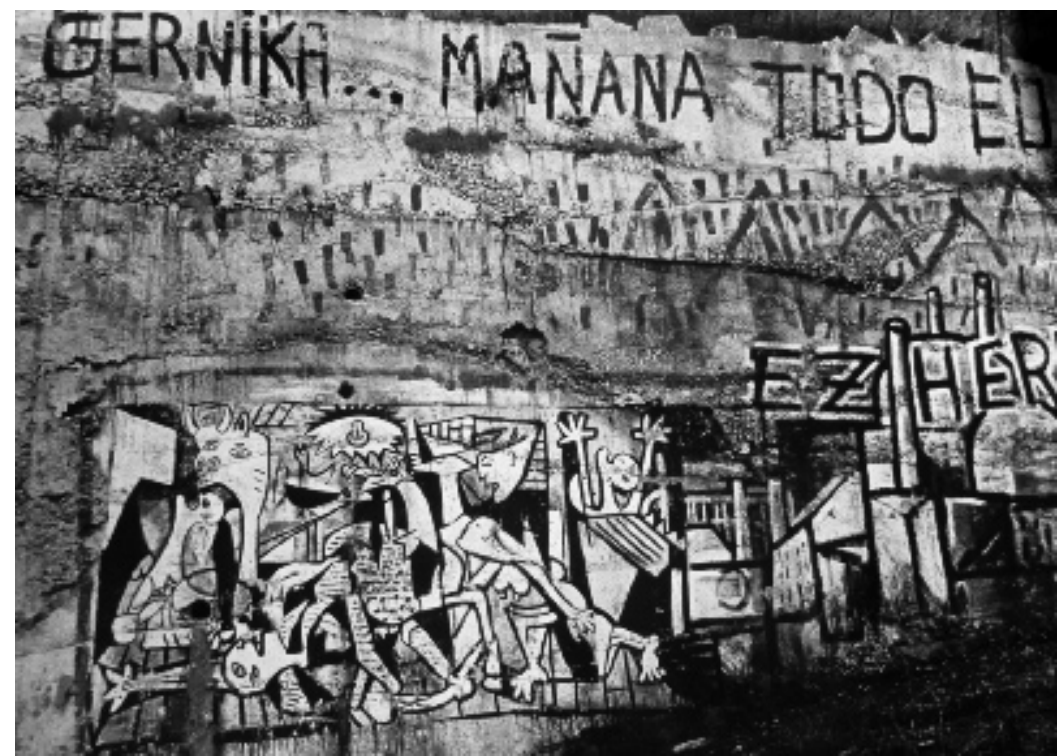

Fig. 3. Mural en el País Vasco, ca. 1975-1980. Foto: Heinz Hebeisen.

Frente a éstos, en los muros del barrio de Portugalete de Madrid se utilizó de nuevo la cultura para reclamar mayores libertades, y no hay más que recordar el lema propuesto por los artistas plásticos para aquellas fiestas de 1976: "Por una cultura popular", que enfatizaba su naturaleza social. Además, el Guernica se convirtió en un lugar o espacio clave, en una tribuna de información, desde la cual recitar, exponer, enseñar, desplegar, comunicar... cualquier teoría, ya fuera política o artística:

"La cultura es la llave de la libertad. Y es que hacer hombres libres y responsables no es otra cosa que poner las condiciones para que los hombres se cultiven, se desarrollen y alcancen a ser en la vida lo que la dignidad personal y comunitaria reclaman de cada ser humano.

19 Angulo Barturen, 1978: 202.

Arch. esp. arte, LXXXVII, 347, JULIO-SEPTIEMBRE 2014, 281-296

ISSN: 0004-0428, eISSN: 1988-8511, doi: 10.3989/aearte.2014.18 
Pero la verdadera cultura del pueblo oprimido es aquella que se forja con él y no para él. La construcción de una sociedad participada reclama también una vida cultural que permita a cada ciudadano sentirse miembro de la vida comunitaria en la que le ha tocado vivir...

Tradicionalmente la cultura ha cabalgado a lomos del individualismo, ya que cultivarse presuponía 'separarse de los demás', abstraerse y tratar de pasar por encima de los otros, como en una competición. En cambio, el pueblo hoy siente el anhelo de una cultura de expresión comunitaria, en la que se reconozca su fuerte vivencia de la solidaridad... "20.

Sin embargo, respecto a esa identidad en Portugalete insisto en el enunciado propuesto por el grupo de Euskadi Guernica obra de Picasso exiliada en USA propiedad de los pueblos de Espa$\tilde{n} a$ (fig. 4). La muerte de Franco entrevió la definitiva oportunidad para España de la recuperación del trabajo de Picasso ${ }^{21}$ y mucho más cuando, en abril del año siguiente, se conmemoraba el cuarenta aniversario del bombardeo. Coyuntura que el pueblo de Guernica, y también el Museo de Bellas Artes de Bilbao, aprovecharon para manifestar e insistir en la vuelta de la obra. Incluso podríamos apuntar la creación de interesantes murales con algunos pasajes del Guernica de Picasso junto a las bombas lanzadas por los nazis en 1937 (fig. 5).

Las primeras elecciones democráticas, en junio de 1977, precipitan los acontecimientos ya que incluso desde Estados Unidos algunos intelectuales como William Rubin (conservador jefe de pintura del MOMA) se oponen a su vuelta al no ser España una República. La reacción por parte del Estado español fue inmediata, en el mes de octubre y en el número 24 del Boletín Oficial de las Cortes se aprobaba, definitivamente, su regreso a España, a pesar de que aún faltaban varios años para que el Boletín del Senado de los Estados Unidos aprobara, el 15 de mayo de 1978, el retorno definitivo de la obra.

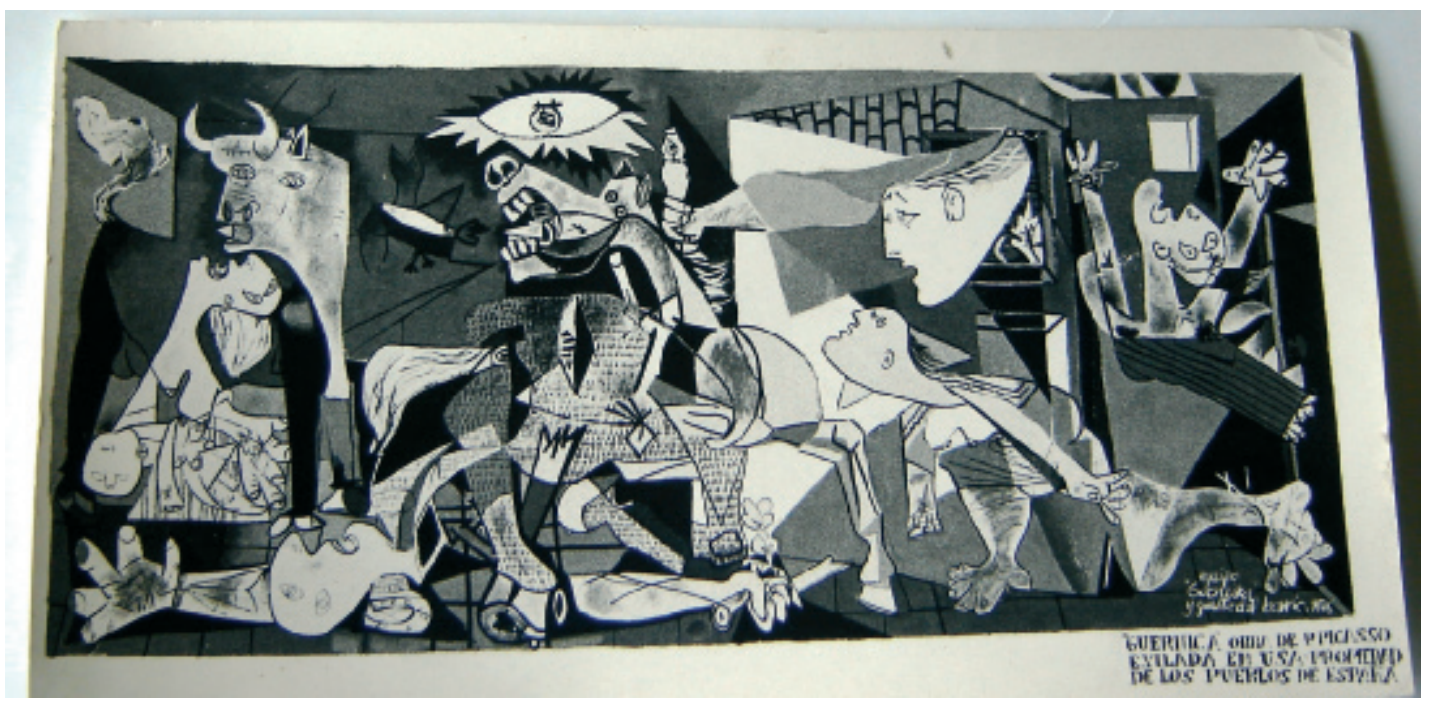

Fig. 4. Postal para las fiestas del barrio de Portugalete, Madrid, 1976.

20 Boletín de las fiestas, Por una cultura popular, Barrio de Portugalete en fiestas del 25 al 29 de junio de 1976, pp. 2 y 3.

21 Vid. "El Guernica podría volver a España”, La Vanguardia española, Madrid, 2-VI-1977 y FortunATA PrIETO, MARÍA, "Guernica", $A B C$, Madrid, 22-V-1977. 
Fig. 5. Mural en el País Vasco, ca. 1977. Foto: Heinz Hebeisen.

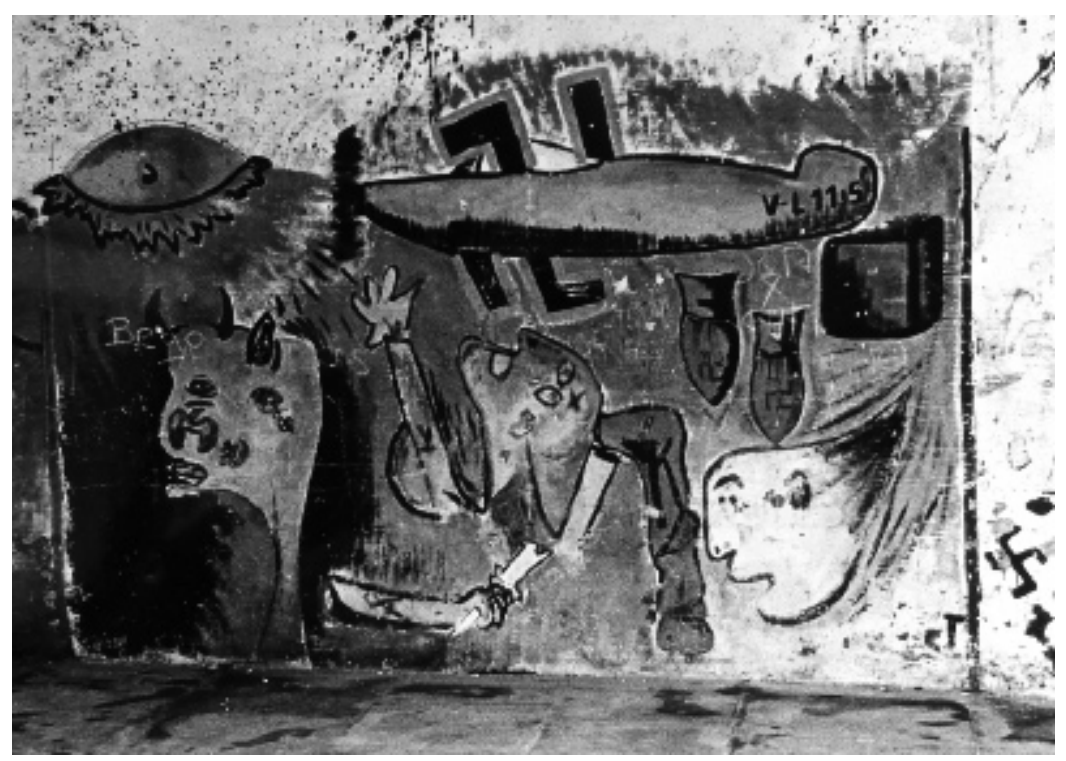

Convertido, pues, en un asunto de Estado comienza todo un itinerario de negociaciones en donde se entrecruzan, en más de una ocasión, las opiniones de políticos y artistas.

No había terminado ese año 1977 cuando en la prensa vasca comienza un intenso debate entre los artistas sobre el destino final de la obra. En el diario DEIA, Agustín Ibarrola publicaba todo un panegírico, "El Guernica de Picasso, a Guernica"22, como consecuencia de unas declaraciones vertidas, en el mismo diario, por Santiago Carrillo y su apoyo al traslado del Guernica al Museo del Prado:

"Los vascos pedimos a todos los pueblos del estado español que contribuyan a que Euskadi pueda acoger junto al árbol de Guernica en el pueblo sagrado de los vascos al Guernica de Picasso.

Euskadi quiere que el Guernica de Picasso vuelva a Guernica, vuelva al lugar donde se produjeron los terribles acontecimientos que motivaron la creación del cuadro más famoso del mundo. Los vascos no deseamos apoderarnos de este patrimonio de los pueblos de España. Creemos que el Guernica situado en Guernica, en Euskadi, fortalecerá la mejor relación y entendimiento entre las gentes de nuestra plurinacional España democrática"23.

Como decíamos al comienzo de este artículo, la búsqueda de unas razones identitarias por parte del pueblo vasco estuvo más presente que nunca (fig. 6). Dejar el Guernica en el Museo del Prado suponía, para muchos, una "desconcentración del patrimonio artístico" o, lo que es lo mismo, un ataque a esa responsabilidad de compartir el legado cultural y artístico español ${ }^{24}$. Mientras que el proyecto propuesto para el pueblo de Guernica, entre otros por Agustín Ibarrola, consistía en la construcción de tres tipologías de museo: internacional, nacional de Euskadi y centro cultural. Además, reivindicaba a los vascos como los principales protagonistas del progra-

\footnotetext{
22 Incluso unos meses antes ya se había publicado "El 'Guernica' para Guernica" en El Punto y Hora de Euskal Herria, núm. 41, 23 y 29-VI-1977.

${ }^{23}$ Ibarrola, Agustín, "El Guernica de Picasso, a Guernica", DEIA, Euskadi, 27-XI-1977.

24 Ibarrola, Agustín, "El bombardeo del 'Guernica”, El País, Madrid, 4-X-1979.
}

Arch. esp. arte, LXXXVII, 347, JULIO-SEPTIEMBRE 2014, 281-296

ISSN: 0004-0428, eISSN: 1988-8511, doi: 10.3989/aearte.2014.18 


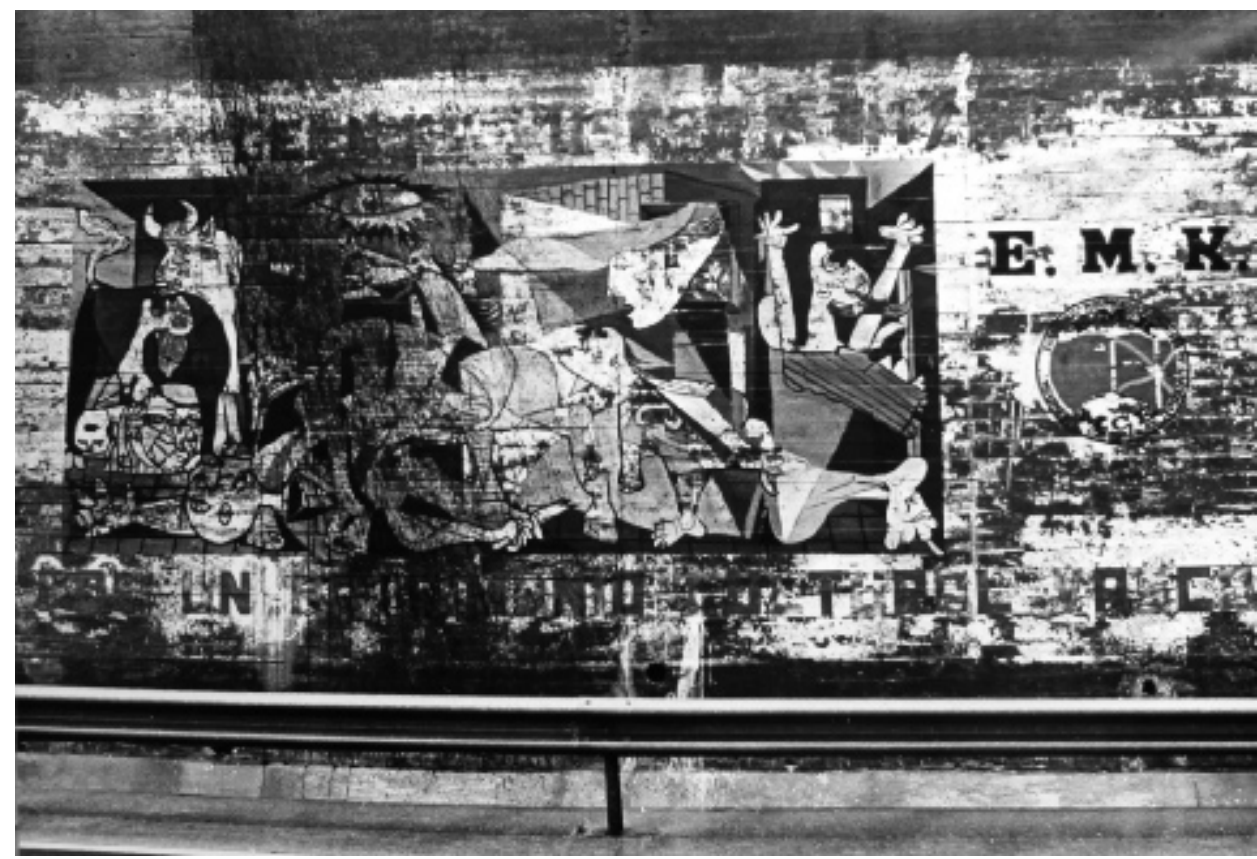

Fig. 6. Mural en el País Vasco con las siglas MCE (Movimiento Comunista de Euskadi), ca. 1975-1980. Foto: Heinz Hebeisen.

ma de recuperación de la obra y, asimismo, confiaba en que podía ser la salvación de la ría de Guernica aunque, como advertía el propio Ibarrola, no sin los riesgos en las negociaciones con un gobierno unilateral y partidista:

“... los vascos queremos montar el necesario museo nacional de Euskadi del arte y de la cultura vasca, el museo capaz de reunir, por fin, junto a las formas artísticas y culturales que abarquen desde las cuevas de Santimamiñe hasta la Euskadi industrial de hoy. Junto al roble del Guernica $y$ de sus evocación al significado democrático de las tradiciones del poder vasco"25.

Por un lado Euskadi y, por otro, la ciudad natal del pintor, Málaga. En mayo y por iniciativa de un grupo de artistas plásticos madrileños se organiza un homenaje a Picasso. En la plaza de la Merced y frente a la casa natal de Picasso se colocaron varias reproducciones del Guernica realizadas por los artistas plásticos. Además se presentó el proyecto homenaje y el cartel de Alberti y se concluyó con una mesa redonda centrada en la libertad del arte de Picasso ${ }^{26}$. Existen también otras fuentes que afirman la intención de realizar, en octubre y en esa misma ciudad, una exposición general de carteles en Homenaje a Picasso ${ }^{27}$.

Finalizaba aquel año 1977 con la presentación del libro Guernica, del poeta Juan Larrea, acompañada de declaraciones políticas tan susceptibles de cualquier interpretación como las del joven político Felipe González: "símbolo de la denuncia feroz contra la destrucción que encama

25 Ibarrola, Agustín, "El Guernica de Picasso, a Guernica”, DEIA, Euskadi, 27-XI-1977.

${ }^{26}$ Archivo personal del artista Ángel Aragonés.

${ }^{27}$ Los carteles serían reproducidos y vendidos en Málaga, si el autor lo autorizaba, y de la venta, el 25\% iría para el autor y el 75\% para cubrir los gastos del homenaje. Archivo personal del artista Ángel Aragonés. 
el totalitarismo fascista... Existe el peligro de los personalismos y partidismos en la apropiación del intento de vuelta del cuadro. El gran dilema es cuándo va a haber un Gobierno que se sienta representativo de los valores que impregnan el Guernica"28.

En 1978, y ante la proximidad de las conmemoraciones del cuarenta y un aniversario de la destrucción de Guernica, el problema de la identidad se hace aún más presente, sobre todo con el apoyo, otra vez, de Agustín Ibarrola mediante nuevos artículos de prensa, documentos como los dirigidos a la Confederación Sindical de Comisiones Obreras de Euzkadi o a la Asociación de Artistas Plásticos de Madrid.

En este sentido habría que anotar también la defensa a esta iniciativa tanto desde las tribunas

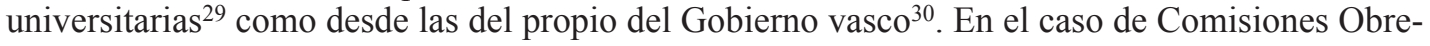
ras de Euskadi, Agustín Ibarrola (como miembro activo) demandaba una adhesión casi inmediata a ese propósito:

"Esto, y mi responsabilidad de artista -por otra parte miembro de comisiones obreras con el carnet número 7- me anima a pedir a Comisiones Obreras que busque la forma adecuada de colaboración con la comisión de Guernica para que sus importantes gestiones se conviertan en una feliz realidad para nuestra clase obrera y todo nuestro pueblo.

Considero que el sindicato las Comisiones Obreras de Euzkadi (sic) habrá de contribuir al desarrollo de nuestra cultura así como al restablecimiento de una personalidad nacional vasca menos determinada por los intereses y por la ideología de la burguesía como hasta ahora ha venido sucediendo. Por eso estoy convencido de que corresponde a este órgano de la clase obrera pronunciarse sobre tan vitales cuestiones para la vida social y cultural del país vasco.

La C.C. O.O. de comisiones obreras (sic) de Ezkadi (sic) debe apoyar decididamente a esta comisión de Guernica. No debe conformarse solamente con unas valiosas declaraciones de sus dirigentes o con la emisión de un comunicado de apoyo moral, debe ir más al fondo, ESTIMO QUE CORRESPONDE ESTABLECER CON LA COMISIÓN DE GUERNICA UNAS ESTRECHAS RELACIONES DE TRABAJO SOLICITANDO DE LA MISMA LA ABERTURA (sic) DE CONVERSACIONES QUE ESTRUCTUREN SU COLABORACIÓN"31.

Más explícitas, si cabe, fueron las tres hojas del comunicado enviado al partido comunista de Euskadi, donde se escudriñaban en diferentes apartados las ventajas de la vuelta del Guernica para el País Vasco. Empecemos por la primera: "Las llaves que pueden empezar a abrir las puertas al Guernika (sic) para Guernica están en Euzkadi (sic)". Hacía referencia a esa futurible apertura de un centro de arte en donde expresar esa ansiada entidad nacional abolida en su mayoría durante el franquismo. Las siguientes: "Bajo la comisión de Guernica surgida de los vecinos todas las demás fuerzas e instituciones" y "La clase obrera en todos los procesos de formación nacional de Euzkadi (sic)". La participación unánime de los sindicatos, de los partidos o todo tipo de organizaciones sociales o culturales y, sobre todo, de instituciones, tan necesarias como el Consejo General Vasco eran primordiales para conseguir la vuelta de la obra. Ibarrola finali-

28 “Presentación del libro 'Guernica' de Juan Larrea”, El País, Madrid, 28-XII-1977.

29 VAdillo Eguino, 2008: 217-233.

${ }^{30}$ El texto que Ibarrola firma para la CCOO de Euskadi menciona el informe entregado al señor José Antonio Maturana (Miembro del Partido Socialista de Euskadi-PSOE, la Unión General de Trabajadores y de las Juventudes Socialistas durante la dictadura franquista y elegido diputado al Congreso en 1977): "Se ha preocupado mucho sobre el momento en que se encuentra la investigación histórica, pero sobre todo, en la recuperación del 'Guernica'. Nos hizo saber que presentara nuestras aspiraciones al CGV (Consejo General Vasco)”, Documento de Agustín Ibarrola, A la C.C.O.O. de Comisiones Obreras de Euzkadi, 7 marzo de 1978, CDB/MNCARS, SIG. 895/2.

31 Documento de Agustín Ibarrola A la C.C.O.O. de Comisiones Obreras de Euzkadi, 7 marzo de 1978, CDB/ MNCARS, SIG. 895/2.

Arch. esp. arte, LXXXVII, 347, JULIO-SEPTIEMBRE 2014, 281-296

ISSN: 0004-0428, eISSN: 1988-8511, doi: 10.3989/aearte.2014.18 
zaba apuntando al partido comunista de Euskadi ${ }^{32}$ como el intermediario idóneo para despejar cualquier duda frente a algún tipo de monopolio ${ }^{33}$.

Su relación con la Asociación de Artistas Plásticos de Madrid y, sobre todo, con algunos de sus miembros como Arcadio Blasco y Carmen Perujo ${ }^{34}$, recordemos aquí que fueron en gran medida los promotores de los murales de Portugalete, le facilita la iniciativa de pedir la adhesión de la Asociación a la comisión de Guernica, al mismo tiempo que envía las peticiones de Comisiones Obreras de Euskadi y las Consideraciones y petición al partido Comunista de Euzkadi (sic) respecto de El Guernica de Picasso y la necesidad vasca de recuperarlo para Guernica:

"En vista de que los artistas plásticos no estamos en este momento en condiciones de establecer una relación profesional colegiada o asociación con pleno sentido colectivo, me veo obligado a pedir a esa Asociación de Artistas Plásticos de Madrid que:

Se pronuncie formalmente en apoyo público a la comisión de Guernica que gestiona la devolución del Gernika (sic) de Picasso a la ciudad de Guernica en la que se produjeron los terribles acontecimientos que motivaron la creación de este mural histórico.

A título personal aconsejo a esa Asociación que a la vez de pronunciarse públicamente a favor de que el Gernika (sic) vuelva a Guernica acompañando de una amplia solidaridad constituya (sic) una comisión de colaboración con la comisión de Guernica para que entre todos lleguemos a convertir a la ciudad sagrada de los vascos en la ciudad de la resistencia, del arte $y$ de la cultura del pueblo vasco, de los pueblos del estado español y de todos los pueblos del mundo" 35 .

Las cartas se recibían en marzo de 1978 y, por lo que he conversado con algunos de los miembros de los Plásticos, no hubo confirmación al respecto. La inmediata celebración del IX Congreso del Partido Comunista (abril de 1978), el primero en la legalidad tras la dictadura, abrió una enorme brecha, ya infranqueable, entre Ibarrola y el PC de Carrillo.

Su propuesta de una ponencia "para recabar expresamente la necesidad de que el Guernika (sic) de Picasso sea gestionado en función de una política de solidaridad con la reconstrucción del pueblo vasco por un ente conjunto que abarque en sentido mixto a la representación de la comisión de Guernica a la del Consejo General vasco a la del Parlamento del Estado español y a la del Gobierno" 36 se concretó en la reclamación de la devolución de la obra de Picasso y su

32 Expresamente pedía a su partido tres gestiones: "1. Presente al Consejo General Vasco una petición de reconocimiento de esta comisión de Guernica que sigue las gestiones de recuperación del Gernika (sic) con todo lo que conlleva de sentido de recuperación tanto de nuestro patrimonio artístico como de reconstrucción de la identidad nacional vasca. 2. Presente al próximo noveno Congreso del Partido Comunista de España una ponencia que recabe expresamente la necesidad de que el Guernika (sic) de Picasso...y 3. Presente la ponencia sobre el Gernika (sic) de Picasso en texto multicopiado que previamente se distribuya entre los asistentes para facilitar el conocimiento del tema". Documento de Agustín IBARRola, Consideraciones y petición al partido comunista de Euzkadi (sic) respeto de el Gernika (sic) de Picasso y la necesidad vasca de recuperarlo para Guernica, marzo de 1978, CDB/MNCARS, SIG. 895/2.

33 "El partido comunista de Euzkadi (sic) puede desbloquear al conjunto de España" e "Insolidaridad y desmotivación por parte del centralismo", en Consideraciones y petición al partido comunista de Euzkadi (sic) respecto de el Gernika (sic) de Picasso y la necesidad vasca de recuperarlo para Guernica, marzo de 1978, CDB/MNCARS, SIG. $895 / 2$.

${ }^{34}$ Es un momento conocido por el artista de autoexilio que coincide también con la muerte de Franco. Se traslada a Madrid y es acogido por sus amigos Arcadio Blasco y Carmen Perujo. Angulo Barturen, JaVIER, 1978:298.

35 Carta de Agustín Ibarrola, A la Asociación de Artistas Plásticos de Madrid, marzo de 1978, CDB/MNCARS, SIG. 895/2

${ }^{36}$ Documento de Agustín Ibarrola, Consideraciones y petición al partido comunista de Euzkadi (sic) respeto de el Gernika (sic) de Picasso y la necesidad vasca de recuperarlo para Guernica, marzo de 1978, CDB/MNCARS, SIG. $895 / 2$. 
instalación en Guernica. Meses antes había solicitado lo mismo en el II Congreso del Partido Comunista de Euskadi.

En este sentido habría que mencionar que el País Vasco estaba inmerso en tensas relaciones con el gobierno central de UCD en busca del Estatuto de Guernica -ni más ni menos en Guernica, ciudad que simbolizaba las libertades vascas- que le permitiría crear un sistema de gobierno parlamentario y un Consejo General Vasco como órgano superior de gobierno preautonómico. No sería hasta el año siguiente, 1979, cuando finalmente se crea el Estatuto de Autonomía del País Vas$\mathrm{co}^{37}$. Estos vaivenes que sufre cierta parte de la sociedad vasca, como la que apoya la participación de Euskadi en el patrimonio artístico y cultural, se verán reflejados en múltiples manifestaciones espontáneas así como en las pintadas sobre muros, en especial, del pueblo de Guernica (fig. 7).

La iniciativa seguirá debatiéndose a nivel nacional, sobre todo cuando el máximo responsable del Partido Comunista de España había declarado como "provincianas" las pro-

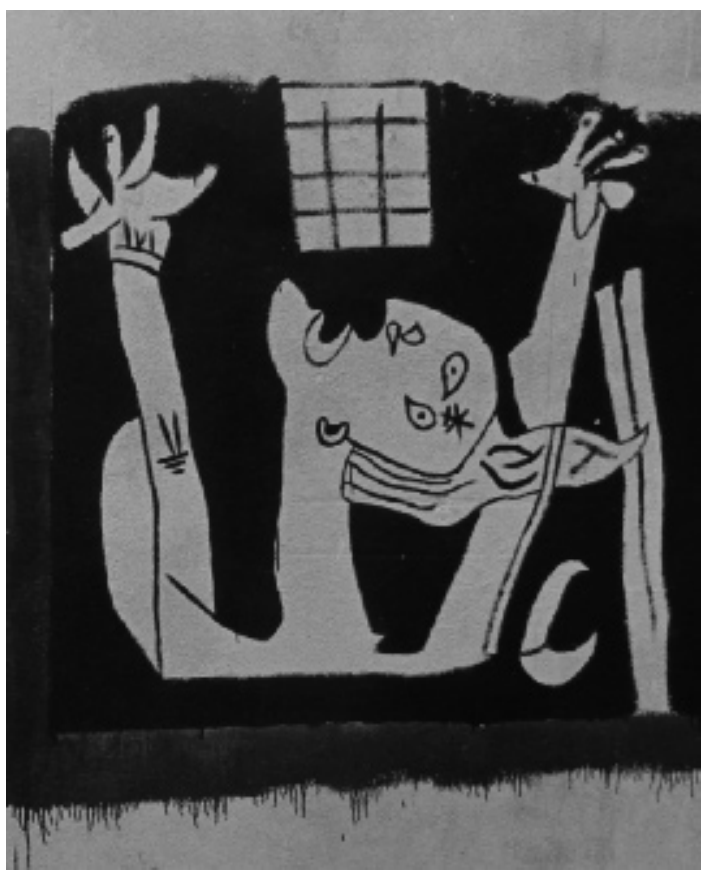

Fig. 7. Mural en una fachada de Eibar, Guipúzcoa, ca. 1975-1980. Foto: Heinz Hebeisen. puestas de llevar la obra al pueblo de Guernica o a la ciudad natal del artista $^{38}$. Es más, el propio Santiago Carrillo declaraba que él mismo y gracias a su amistad con Picasso y Jacqueline podría ser un intermediario excepcional en todas las gestiones:

"El Gobierno nunca ha mostrado interés, a pesar de que yo siempre me he mostrado dispuesto a actuar para que el 'Guernica' volviera a España. Nunca se ha tenido interés de que nosotros interviniéramos en la gestión. Yo no sé si el Gobierno tenía interés en que el cuadro viniera rápidamente o quería prolongar la cosa hasta más tarde por la carga histórica que tiene. Y en cuanto al centenario, no me extraña la actitud gubernamental, porque desde el punto de vista cultural han cambiado poco las cosas del franquismo hasta hoy" ${ }^{39}$.

En definitiva, asistimos a una parte destacada de ese significado sociopolítico del Guernica en los últimos años de la década de los setenta. Si durante el franquismo la obra se había convertido en buque insignia del comunismo y otros partidos de izquierda, y eso a pesar, como recuerda Juan Manuel Bonet ${ }^{40}$, de haber sido admirado por intelectuales afines al régimen como Eugenio D’Ors o Giménez Caballero, durante la Transición fue una moneda de cambio para in-

${ }^{37}$ La devolución definitiva de la obra a la capital de España supuso para los nacionalistas vascos "un auténtico secuestro del gobierno de Madrid". Clark, ToBy, 1997: 45.

38 Figueroa, Juan, "Carrillo: 'Yo pude ser intermediario en lo del Guernica", La Calle, Madrid, núm. 78, 18-24IX-1979.

39 Figueroa, JuAn, "Carrillo: 'Yo pude ser intermediario en lo del Guernica"”, La Calle, Madrid, núm. 78, 18-24IX-1979.

40 Bonet, Juan Manuel, "Picasso: objetivo 1981”, La Calle, Madrid, núm. 76, 4-10-IX-1979.

Arch. esp. arte, LXXXVII, 347, JULIO-SEPTIEMBRE 2014, 281-296

ISSN: 0004-0428, eISSN: 1988-8511, doi: 10.3989/aearte.2014.18 
tereses particulares. En este sentido quiero recordar que no sólo se trataba del tema del Guernica sino de todo lo relacionado con Picasso; por ejemplo, el asalto a la galería madrileña Theo por una banda de extrema derecha, en donde se exhibían 28 grabados de la Suite Vollard, de los cuales 24 fueron destruidos ${ }^{41}$. También, y como consecuencia de ese acto vandálico anterior, se celebraría una exposición homenaje a Picasso en la librería Antonio Machado con obras realizadas por más de cien artistas ligados a la Asociación de los Plásticos de Madrid, que sería prohibida después de estar abierta sólo medio día ${ }^{42}$, o la detención y fallo del Supremo a dos años de cárcel para el crítico de arte José María Moreno Galván por dar una conferencia sobre Picasso en la Facultad de Ciencias de la Universidad Complutense ${ }^{43}$ : "haciendo resaltar la personalidad ideológica del artista cuyo aniversario del nacimiento se conmemoraba con frecuentes alusiones al denominado Partido Comunista, en tanto que durante la alocución personas no identificadas portaban y exhibian desplegada una pancarta roja con el emblema de la hoz y el martillo, arrojaban impresos en los que se consignaba una frase subversiva y coreaban con gritos algunos pasajes del discurso... "44.

Aquel altercado tuvo una gran repercusión entre los artistas e intelectuales, produciéndose en el Museo del Prado uno de los encierros más recordados por muchos ${ }^{45}$.

A punto de terminar la década de los setenta Ibarrola pensaba que el asunto Guernica era ya una cuestión zanjada, culpando al gobierno central y llamando de nuevo a la opinión pública ${ }^{46}$. Sin embargo, el Partido Comunista Español vivió un nuevo sobresalto cuando se lanzó a la calle

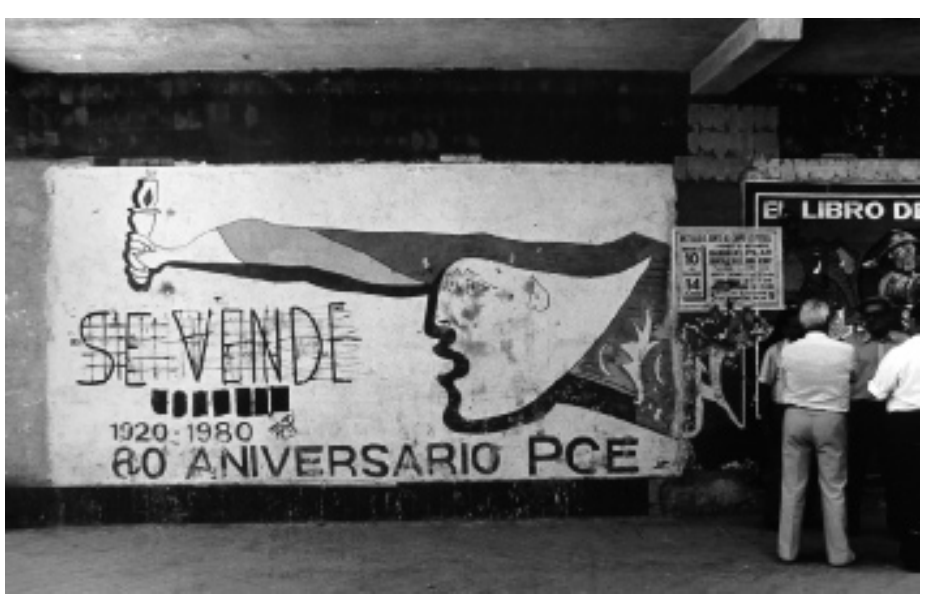

Fig. 8. Mural del 60 aniversario del PCE, Madrid, 1980. Foto: Heinz Hebeisen. (pintado o pegado en sus muros) el lema de su "60 aniversario (1920-1980)" con la célebre imagen de Picasso. Curiosamente el fragmento elegido fue el mismo que el de Portugalete de 1975 pero incluyendo la siguiente leyenda: "Se vende" (fig. 8). Pese a todo, aún continuaban las frenéticas negociaciones del Estado con el MOMA y no sería hasta el 9 de septiembre de 1981 cuando el cuadro se descolgaría de dicho museo. En esas mismas fechas, otros, como el historiador Juan Manuel Bonet, publicaban frases lapidarias: "Ojalá llegue

41 "Detenidos los autores del atentado contra la exposición de Picasso", ABC, Madrid, 7-XI-1971.

42 Documento, 2 de diciembre de 1977, CDB/MNCARS, SIG. 895/2. 11 y "Prohibida una exposición homenaje a Pablo Picasso", ABC, Madrid, 13-XII-1971.

43 "Tribunales", $A B C$, Madrid, 9-III-1974.

44 "Fallo del Supremo: dos años de cárcel para el señor Moreno Galván”, La Vanguardia española, Madrid, 9-III1974.

45 La Asociación de Artistas Plásticos de Madrid conserva una lista incompleta con los nombres de algunos de los encerrados en el Museo del Prado, entre ellos caben destacar: Alcaín, Arenillas, Arcadio Barjola, Blasco, Bonanni, Calabuig, Chirino, Genovés, Guinovart, Iraola, Mompó, Lucio Muñoz, Millares, Saura, Sempere, Pablo Serrano, Tito, Úrculo, José Vento y Salvador Vitoria. Documento, Para el archivo, s/f., CDB/MNCARS, SIG. 892/16.

46 Ibarrola, Agustín, “El bombardeo del “Guernica”, El País, Madrid, 4-X-1979. 


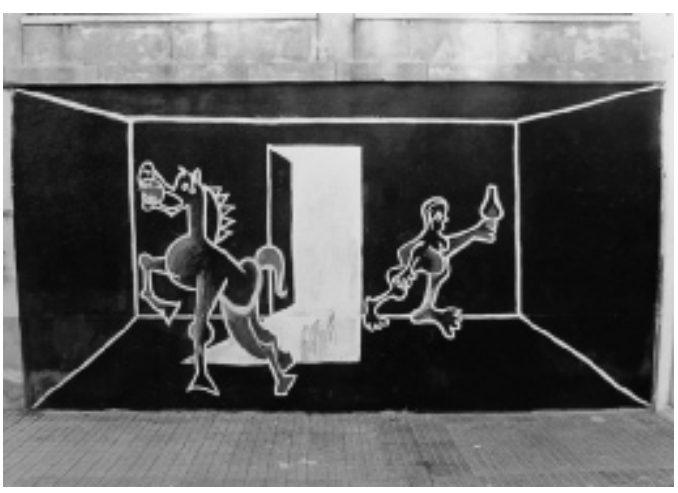

Fig. 9. Mural del barrio del Pilar, Madrid, ca. 19751980. Foto: Heinz Hebeisen.

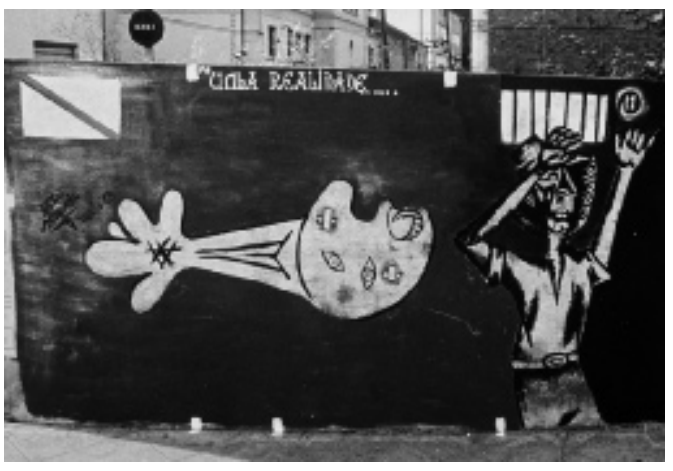

Fig. 11. Mural en el Barco de Valdeorras, Orense, ca. 1975-1980. Foto: Heinz Hebeisen.

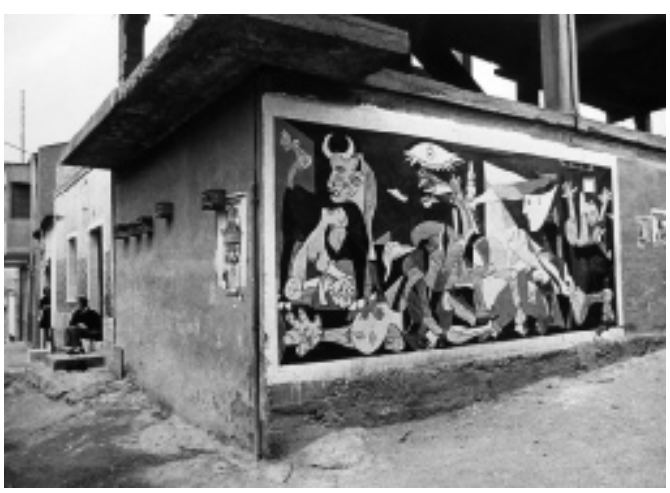

Fig. 10. Mural en Cartagena, Murcia, ca. 19751980. Foto: Heinz Hebeisen.

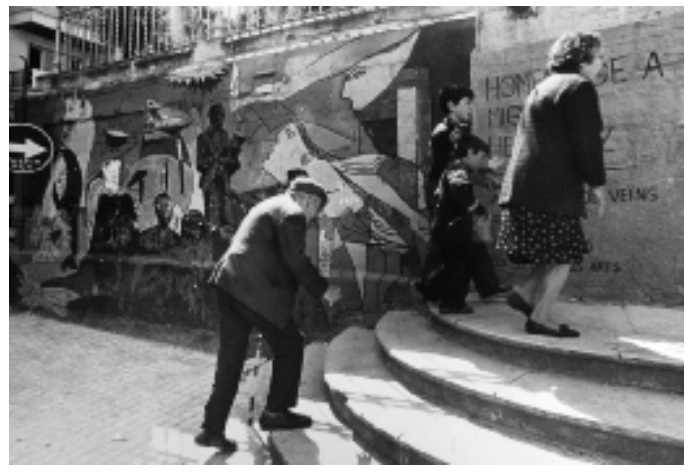

Fig. 12. Mural en Alcoy, Alicante, 1976. Foto: Heinz Hebeisen.

pronto el día en que Picasso no sea ya ni escandalosa laguna oficial ni vestigio mitológico y 'progre' del tiempo de la resistencia" 47 .

No fueron -como hemos visto- los únicos homenajes a la inmortal imagen de Picasso. Podemos mencionar otros menos conocidos como los murales que se pintaron espontáneamente a lo largo de toda la Península: Alicante, Málaga, el barrio del Pilar en Madrid (fig. 9), Cartagena (fig. 10), Galicia (fig. 11), Alicante (fig. 12), etc. Ese clima de incertidumbre política traducido en las representaciones del Guernica traspasó nuestras fronteras hacia países más democráticos, tal y como demuestran los reportajes fotográficos realizados por Heinz Hebeisen ${ }^{48}$.

47 Bonet, Juan Manuel, "Picasso: objetivo 1981”, La Calle, Madrid, núm. 76, 4-10-IX-1979.

48 Staber, Margit, "Mauer-Gedanken" Neue Zürcher Deitung, Zurich, 15 y 16-I-1977; HeBeisen, HeInZ, "Von der grauen zur farbigen Stadt", Jugend Woche, núm. 3, III-1979; HotTinger, ARnold, "Picassos 'Guernica' als Volkskunst", Neue Zürcher Zeitung, 12 y 13-IV-1980; “Guernica’ auf Spaniens Hausmauern”, Luzerner Tagblatt, Lucerna, 26-IX1981; KreIs, Georg, "Guernica: Kunst und Politik”, Basler Magazin, Basel, 29-VIII-1981; HeBeISEN, HeInZ, "Guernica als Vorbild für Politgraphik", Tages-Anzeiger, 24-IX-1981 y BiLleter, FritZ “Guernica: Bild und Wirkung”, TagesAnzeiger, 17-X-1981. 
En poco tiempo se pasó de su apropiación por el ideario comunista o progresista a convertirse en el emblema de la futura democracia que se enfrentaba a nuevos retos como la aparición de centrales nucleares o el ingreso en la OTAN, con numerosas manifestaciones en contra donde con frecuencia ondeó la imagen del Guernica.

En definitiva, una de las obras más conocidas e icónicas de Picasso, el Guernica, se convirtió durante la dictadura, la transición y la democracia española en un símbolo de libertad, de reconciliación nacional, de significado sociopolítico, sobre todo, de identidad para el pueblo vasco e inclusive de símbolo político universal de lucha. Las revisiones de la obra son constantes ${ }^{49}$ por ejemplo; la última es la exposición Unguernica en la Fundación Picasso Museo Casa Natal de Málaga por el artista norteamericano Ray Smith ${ }^{50}$.

Pero, sin duda, una de las más polémicas ha tenido lugar hace unos días, como ha sido la entrega de armas de la banda terrorista ETA teniendo de telón de fondo la imagen del Guernica. La escena resume a la perfección la apropiación interesada que unos pocos han hecho del significado genérico de libertad que tiene la obra.

\section{BIBLIOGRAFÍA}

Angulo Barturen, Javier, Ibarrola, ¿Un pintor maldito?, L. Haranburu, San Sebastián, 1978, pp. 202 y 298. Amondarain, José Ramón (comisario), Tiempo y urgencias (Guernica), cat. exp. Vitoria, ARTIUM, mayoseptiembre, 2012

Clark, Toby, Arte y propaganda en el S. XX, Madrid, Akal, 1997, pp. 39-45.

De Haro García, Noemí, Estampa Popular: Un arte crítico y social en la España de los años sesenta, Tesis Doctoral inédita, Facultad de Geografía e Historia, Universidad Complutense, Madrid, 2010.

García García, Isabel, "Barrios intervenidos artísticamente durante el último franquismo", Arte y Ciudad, Revista de Investigación, núm. 3, Madrid, 2013, pp. 477-490.

Gorris, Josep María, El juego y el juguete, Ed. Queimada, Madrid, 1981.

Haro González, Salvador y Soto Calzado, Inocente, "Viñetas en el frente". En Haro González, Salvador, Rafart i Planas y Soto Calzado, Inocente (comisarios), Viñetas en el frente, cat. exp., Málaga, Museo Picasso de Málaga, 2011, pp. 15-28.

Roseras Carcedo, Elena (comisaria), Guernica de Picasso: Historia, memoria e interpretaciones, cat. exp. ARTIUM, Vitoria, abril-septiembre, 2012.

Vadillo Eguino, Miren, "Transformaciones artísticas e instauración de un modelo cultural en el nuevo gobierno vasco", Ondare 26, Cuadernos de Artes Plásticas y Monumentales, Donostia-San Sebastían, 2008, pp. 217-233.

Van Hensbergen, Gijs, Guernica: la historia de un icono del siglo XX, Debate, Madrid, 2005.

Fecha de recepción: 21-X-2013

Fecha de aceptación: 18-II-2014

49 Hace poco tiempo, ARTIUM, Centro-Museo Vasco de Arte Contemporáneo, coincidiendo con el 75 aniversario del bombardeo de Gernika y la realización de la obra, dedicó varias exposiciones, entre ellas cabe destacar: RosERAS CARCedo, Elena (comisaria), Guernica de Picasso: Historia, memoria e interpretaciones, cat. exp. ARTIUM, Vitoria, abril-septiembre, 2012 y AMONDARAIn, José RAMÓn (comisario), Tiempo y urgencias (Guernica), cat. exp. Vitoria, ARTIUM, mayo-septiembre, 2012.

50 RaY Smith, Unguernica, Fundación Picasso Museo Casa Natal, noviembre de 2013-abril de 2014. 